\title{
1 Assessing the utility of eDNA as a tool to survey reef-fish communities in
}

\section{2 the Red Sea}

3

4 Joseph D. DiBattista ${ }^{1 *}$, Darren J. Coker ${ }^{2}$, Tane H. Sinclair-Taylor ${ }^{2}$, Michael Stat ${ }^{1}$, Michael L.

$5 \quad$ Berumen $^{2}$, and Michael Bunce ${ }^{1}$

6

$7{ }^{1}$ Trace and Environmental DNA Laboratory, Department of Environment and Agriculture,

8 Curtin University, Perth, WA 6102, Australia

$9 \quad{ }^{2}$ Division of Biological and Environmental Sciences and Engineering, King Abdullah

10 University of Science and Technology, Thuwal 23955-6900, Saudi Arabia

11

12

*corresponding author: Joseph D. DiBattista, Trace and Environmental DNA Laboratory,

Department of Environment and Agriculture, Curtin University, Perth, WA 6102, Australia

14 E-mail: josephdibattista@gmail.com

15

ORCID: 0000-0002-5696-7574

16

17 Keywords: Biodiversity, Coral reef, Environmental DNA, Metabarcoding, Next-generation sequencing 
Abstract

21 Relatively small volumes of water may contain sufficient environmental DNA (eDNA) to detect target aquatic organisms via genetic sequencing. We therefore assessed the utility of eDNA to document the diversity of coral-reef fishes in the central Red Sea. DNA from seawater samples was extracted, amplified using fish-specific 16S mitochondrial DNA primers, and sequenced using a metabarcoding workflow. DNA sequences were assigned to taxa using available genetic repositories or custom genetic databases generated from reference fishes. Our approach revealed a diversity of conspicuous, cryptobenthic, and commercially relevant reef fish at the genus level, with select genera in the family Labridae over-represented. Our approach, however, failed to capture a significant fraction of the fish fauna known to inhabit the Red Sea, which we attribute to limited spatial sampling, amplification stochasticity, and an apparent lack of sequencing depth. Given an increase in fish species descriptions, completeness of taxonomic checklists, and improvement in specieslevel assignment with custom genetic databases as shown here, we suggest that the Red Sea region may be ideal for further testing of the eDNA approach.

\section{Introduction}

37 Coral reefs represent less than $0.02 \%$ of the surface area of our oceans and yet host more than $25 \%$ of the recognized marine species (Spalding et al. 2001). In the Red Sea, coral reefs are characterized by their high and unique biodiversity (DiBattista et al. 2016b), historical isolation (DiBattista et al. 2016a), and extreme seasonal and spatial fluctuations in abiotic and

41 biotic factors (Raitsos et al. 2013). Yet compared to other major global reef systems (e.g.,

42 Great Barrier Reef), the associated communities of the Red Sea are considerably understudied (Berumen et al. 2013). 
44 Community assemblages of reef fishes have historically been documented through diveroperated underwater visual census methods (UVC; Roberts et al. 1992) or baited remote underwater video surveys (BRUVs; Harvey et al. 2012). Even though these standardized survey methods are ideal for identifying large, mobile, and conspicuous species, the smaller, more cryptic species are often missed (see Ackerman and Bellwood 2000). In recent years, genomic approaches have shown considerable potential for identifying diversity in marine environments, although many of these studies are based on fixed, benthic sampling methods (e.g., Leray and Knowlton 2015). Environmental DNA (eDNA; i.e., genetic material sourced from microbes or that which has been shed from multicellular organisms), on the other hand, has proven useful in monitoring the presence/absence of invasive species and assessing biodiversity in aquatic environments (e.g., Thomsen et al. 2012).

The majority of macrobial eDNA investigations to date have been species-specific, but multi-species PCR in combination with high-throughput sequencing (metabarcoding) can extend these methods to reveal a greater diversity of species in our oceans (e.g., Miya et al. 2015). Even though the sensitivity of these high-throughput assays is likely influenced by the frequency of cell shedding, water flow (currents or tides), and rates of DNA degradation, in most cases this approach has advantages when combined with existing monitoring efforts, including operating at a reduced cost. Given that small volumes of water may contain sufficient eDNA to sequence and detect target aquatic organisms (Thomsen et al. 2012; Miya et al. 2015), our study is the first to apply this non-invasive survey method and assess its utility to document the diversity of fishes inhabiting Red Sea coral reefs.

\section{Materials and methods}

\section{Study site}



Thuwal, Saudi Arabia (Fig. 1). Seven sampling sites were located on inshore, midshore, and offshore reefs, with six replicate seawater samples $(500 \mathrm{~mL}$ per sample) taken from both the exposed and sheltered sides of each reef (a total of 12 replicates from each reef). Four replicate samples were also taken from the King Abdullah University of Science and Technology (KAUST) boat harbor, where there are relatively fewer reef-fish species. Multiple precautions were taken to minimize contamination with exogenous eDNA, including rinsing all water bottles and the filtering apparatus in a $10 \%$ bleach solution prior to use and between each sampling. Moreover, seawater was collected only at the surface (top 20 $\mathrm{cm}$ ), on the windward side of the research vessel, and within $5 \mathrm{~m}$ of the reef, changing latex gloves in between samples. To minimize eDNA degradation, the samples were filtered immediately on the research vessel using a peristaltic pump (Sentino microbiology pump, Pall Life Sciences, MI) and $47 \mathrm{~mm}(0.45 \mu \mathrm{m})$ micronylon sterilized membranes (Pall Life Sciences), which were then placed in individual plastic bags and stored on ice prior to being frozen at $-20{ }^{\circ} \mathrm{C}$ until eDNA extraction. All extractions were performed within $5 \mathrm{~d}$ of collection to limit the decay of template material on the membranes.

\section{DNA extraction}

Genomic DNA was extracted in a sterile environment at KAUST using a DNeasy blood and tissue kit (Qiagen Inc., CA) following the manufacturer's protocol with a few modifications: (1) $360 \mu \mathrm{L}$ of ATL tissue lysis buffer and $40 \mu \mathrm{L}$ proteinase $\mathrm{K}$ was added to $1 / 3$ of the filter membrane that had been cut up in a UV hood; (2) the filter membrane was digested for $3 \mathrm{~h}$; (3) the supernatant following digestion was removed and transferred to a clean $2-\mathrm{mL}$ tube where $400 \mu \mathrm{L}$ of absolute ethanol and $400 \mu \mathrm{L}$ of AL lysis buffer was added; (4) two separate microcentrifuge spins with the digested solution were used to pass all of the DNA through the 
filter column; (5) all samples were eluted in one step using $100 \mu \mathrm{L}$ of AE buffer; and (6) extraction controls, for which all steps remained the same except for the addition of the filter membrane, were included for each set of 12 samples.

\section{Fusion-tag qPCR}

Quantitative PCR (qPCR) experiments were conducted in a separate, dedicated laboratory at Curtin University in Australia where all benches and utensils were routinely cleaned with bleach and UV sterilized. This approach allowed us to: (1) recover fish 16S mitochondrial DNA barcode sequences of $\sim 200 \mathrm{bp}$ from mixed samples with the primers $16 \mathrm{SF} / \mathrm{D}$ (5) GACCCTATGGAGCTTTAGAC 3') and 16S2R-degenerate (5' CGCTGTTATCCCTADRGTAACT 3') (modified from Deagle et al. 2007); (2) add multiple forward $(N=8)$ and reverse $(N=25)$ fusion tags to the qPCR products that each contained a unique 10 bp Illumina adaptor sequence; and (3) estimate final concentrations of the DNA amplicons using SYBR Green as a reporter of fluorescence. All qPCRs were run in triplicate and included "no template" controls to check for sample cross-contamination. qPCR reactions (25 mL) consisted of the following: 10x PCR Buffer (Bioline, London, U.K.), 0.25 $\mathrm{mM} \mathrm{MgCl} 2,10 \mathrm{mM}$ dNTPs, $0.4 \mathrm{mg} \mathrm{mL}^{-1}$ bovine serum albumin, 1.25 U Ampli-Taq Gold (Applied Biosystems, CA), $20 \mathrm{mM}$ primers, and $2 \mu \mathrm{L}$ undiluted DNA extract. Cycling conditions were as follows: $95{ }^{\circ} \mathrm{C}$ for $5 \mathrm{~min}$, followed by 45 cycles of $95{ }^{\circ} \mathrm{C}$ for $30 \mathrm{~s}, 54{ }^{\circ} \mathrm{C}$ for $30 \mathrm{~s}$, and $72{ }^{\circ} \mathrm{C}$ for $45 \mathrm{~s}$, with a final step of $72{ }^{\circ} \mathrm{C}$ for $10 \mathrm{~min}$. Failed amplifications were not repeated, resulting in fewer than 12 replicates per sampling station. DNA amplicons from each sample were pooled in equimolar concentration based on qPCR endpoints and quantification on a LabChip GX Touch (PerkinElmer Health Sciences, MA), size-selected using a Pippen Prep (Sage Science, MA), and then purified using a QIAquick PCR Purification Kit (Qiagen Inc., CA) following the manufacturer's protocol. The final library 
was quantified on a LabChip GX Touch followed by sequencing in the TrEnD Laboratory at

Curtin University on an Illumina MiSeq platform using 300 cycle MiSeq V2 reagent kits and

(doi:10.5061/dryad.1pm20).

\section{Bioinformatic filtering}

Sequences were assigned to samples, quality filtered, and trimmed in Geneious Pro v 4.8.4

(Drummond et al. 2009) using the following workflow: (1) reads containing imperfect

Illlumina adaptor sequences were discarded; (2) reads containing imperfect forward or reverse fish $16 \mathrm{~S}$ primer sequences were discarded; (3) reads were de-multiplexed based on the combined forward and reverse MID sequences; (4) reads with imperfect MID barcode sequences were discarded; (5) reads smaller than 160 bp were discarded; (6) singletons were discarded; and (7) chimeric sequences were flagged and discarded using USEARCH v 8.0.1623 (Edgar 2010).

\section{Taxonomic assignment}

We interrogated the NCBI BLASTn database (March 2016) on the Magnus Cray XC40 system located at the Pawsey Supercomputing Centre at Technology Park in Western Australia, with our 16S sequences in FASTA format. BLASTn results were imported into MEtaGenome ANalyzer (MEGAN) v 5.11.3 (Huson and Weber 2013), and taxonomic identities were assigned to genus or species (where possible) based on the lowest common ancestor (LCA) algorithm using the following settings: minimum number of reads $=2$; minimum bit score $=300$; top percent to be considered $=10 \%$; and minimum complexity $=$ not considered. A similarity of $95 \%$ was accepted for a genus-level match and $98 \%$ for a 
with LCA were further evaluated against expert knowledge of species distributions and the most up-to-date checklist of Red Sea fishes (DiBattista et al. 2016b and references therein).

To be conservative, matches at the species level were not accepted if that taxon was not known from the Red Sea or if $16 \mathrm{~S}$ sequences from all species within that genus were not available on NCBI or in our custom genetic database.

Given multiple hits to poorly archived fish $16 \mathrm{~S}$ sequences on NCBI, an issue raised by Pleijel et al. (2008), in addition to fish species not found in the Red Sea (16 of the 25 species assigned), a modified BLASTn search was performed against a curated custom genetic database of Red Sea fishes, within which we selected a single representative 16S sequence from all reef-fish species found in the Red Sea that were available on NCBI. Where possible, sequences were extracted from datasets published by trusted sources and those that had vouchered their whole specimens at museums (Electronic supplementary material, ESM, File S1). We additionally generated $16 \mathrm{~S}$ sequences for 38 fish species sampled in the Red Sea to add to the custom database, which provided a total of 474 of the 1071 known reef-fish species from the region (DiBattista et al. 2016b).

\section{Results and discussion}

Our 16S eDNA metabarcoding approach at seven reef sites and a boat harbor in the central Red Sea revealed between 26 to 46 genera of fish (out of 511 known genera; DiBattista et al. 2016b) based on 250,145 total DNA sequences. These genera represent diverse conspicuous (e.g., Chaetodon), cryptobenthic (e.g., Eviota), numerically abundant (e.g., Pseudanthias), and commercially relevant shorefish (e.g., Cephalopholis, Epinephelus, Lethrinus, and Lutjanus) known to inhabit the Red Sea (DiBattista et al. 2016b). Our eDNA assignment approach using the NCBI database and our custom genetic database identified 12 or 6 out of the 21 most abundant conspicuous reef-fish genera identified by a recent UVC study (Roberts 
et al. 2016), respectively, and between $17 \%$ to $42 \%$ of these genera were only detected at a single site. This difference in detection capability may be due to the limited spatial scale of our sampling ( $<1 \%$ of the eastern Red Sea coastline) or our lack of ability to resolve species based on short but amplifiable 16S fragments of DNA.

DNA sequencing was successful for 53 of the 88 replicate seawater samples collected at reefs in the central Red Sea (Fig. 1). Of these replicates, there was a modest bias towards amplification success on the sheltered side versus the exposed side of the reefs (31 vs 22), which may indicate increased suspension of organic material or water residency time in the former; sampling effort should be focused here in future studies. However, given the lack of data for the exposed side of the reefs, we combined data from both sides of the reef for all downstream analyses. DNA degradation, primer biases, or a lack of template DNA may have all played a role in the samples that failed to amplify. Moreover, for eDNA surveys such as this, it is difficult to know a priori what the DNA template concentration will be in the water column. We recovered limited amounts of template, a finding that contrasts with other studies (Miya et al. 2015), but is important to consider when designing eDNA surveys in an environment for the first time.

Our non-invasive survey method revealed a trend in sampling effort at some (but not all) reefs based on the number of cumulative fish genera assigned per replicate (Fig. 2a). For example, no new genera were assigned after as little as one replicate out of four total replicate seawater samples taken from KAUST harbor, whereas new genera continued to be assigned for two reefs that had at least eight or nine replicates included in the analysis. Indeed, taxonomic assignment to genus had not yet reached saturation at four of the eight reefs based on the upward trajectory of the accumulation curves. This suggests that 12 or more replicates, based on the volume of seawater that we filtered in this study $(500 \mathrm{~mL})$, may be required. In contrast, there was no clear bias in this "saturation trend" among inshore, midshore, or 
offshore reefs. No relationship was observed between the number of $16 \mathrm{~S}$ sequences generated per reef and the number of genera assigned $\left(r^{2}=0.037, p=0.17\right.$; Fig. $\left.2 b\right)$, although when we removed two outlier data points that appeared to drive the regression (>2 SD, both from $\mathrm{Al}$ Fahal South), this relationship became significant $\left(r^{2}=0.45, p<0.0001\right)$, indicating a clear benefit of more replicates and increased sequencing coverage per replicate, also highlighted by rarefaction analysis of randomly selected samples (ESM Fig. S1).

When the number of unique sequences per genus was averaged across each reef we identified over-represented genera (e.g., Chlorurus, Halichoeres, Scarus) at some, but not all reefs based on assignments made using the NCBI database (Fig. 3a) and our custom genetic database (Fig. 3b). This may indicate biases in the workflow that preferentially target these genera or increased DNA concentrations of these genera present in seawater samples.

Moreover, some of the common genera in the Red Sea were notably absent from our data (e.g., Apogon, Coris, Gobiodon, Pseudocheilinus, Pygoplites; Roberts et al. 2016). Low values for the average number of unique sequences in most cases (Fig. 3a: mean $=8.08 \pm$ 3.65 SE, median $=0.67$; Fig. $3 \mathrm{~b}$ : mean $=5.02 \pm 2.65$, median $=0.65)$ further suggests that there may be a clear benefit of increased coverage per reef by either increasing the number of replicates ( $>12$ replicates), increasing the volume of water filtered $(>500 \mathrm{~mL})$, decreasing the pore size of the filter membrane to capture smaller particles $(<0.45 \mu \mathrm{m})$, or generating higher numbers of metabarcoding reads. The benefit of generating higher numbers of metabarcoding reads is supported by our rarefaction analysis of randomly selected samples from a single reef, where there was considerable variability in the level of sequencing at which saturation was reached for assignment of genera (ESM Fig. S1). Based on heatmaps (Fig. 3), there was also an indication that different reefs had different compositions of fish. Although previous aquatic studies have attempted to infer the abundance of taxa from the number of sequence reads (amphibians: Pilliod et al. 2013; fish: Mahon et al. 2013; Lacoursière-Roussel et al. 
2016), we chose to avoid this inference due to confounding factors potentially skewing the proportions of reads, including fluctuating environmental conditions, variable rates of DNA degradation (Dejean et al. 2011), and low template numbers (Murray et al. 2015).

Even with our custom genetic database, less than half of all Red Sea species were represented with a $16 \mathrm{~S}$ barcode sequence (474 of the 1071 species). Indeed, some speciose genera were under-represented in our custom database, with $\leq 10 \%$ of the species in their respective genera with a $16 \mathrm{~S}$ barcode sequence (ESM File S1, Fig. S2). Nonetheless, almost twice as many taxa were confidently assigned to species using our custom database $(N=16)$ versus the NCBI database $(N=9)$, despite the same conservative criteria being used in both cases (Table 1).

Caveats to consider when barcoding seawater samples based on 16S fish DNA include misidentification in the NCBI reference database, incomplete lineage sorting or hybridization between species, or (in our case) a dearth of vouchered sequences from reef fish sampled in the Red Sea. Also, because $16 \mathrm{~S}$ is a much shorter read for eDNA applications, the taxonomic resolution at the species level is weak, particularly in the Red Sea. Indeed, we have previously shown that intraspecific divergence of reef fish from adjacent Indian Ocean populations can be comparable to interspecific comparisons (DiBattista et al. 2013) and that cryptic lineages are not uncommon (DiBattista et al. 2017). These caveats are not unique to our study or restricted to reef fish, but can be mitigated with increased regional barcoding initiatives, and may be less of an issue for better-characterized coral reefs (e.g., Great Barrier Reef). The benefits of this approach despite its equivocal outcome is that it may prove to be more cost-effective than expensive field time, and also that eDNA studies are not limited by poor environmental conditions (e.g., visibility, hazardous conditions) or a lack of taxonomic expertise. These initial eDNA trials from the Red Sea show that the method has several 
potential applications but that surveys will need to be carefully designed given the number of potentially confounding factors.

\section{Acknowledgements}

This study was funded by KAUST award number CRG-1-2012-BER-002 and baseline research funds to M.L.B., as well as a Curtin University Early Career Research Fellowship to J.D.D. The authors would like to acknowledge KAUST's Coastal and Marine Resources Core Lab for logistical support, as well as Matthew Power, Megan Coghlan, and Brendan Chapman for DNA sequencing assistance.

\section{References}

Ackerman JL, Bellwood DR (2000) Reef fish assemblages: a re-evaluation using enclosed rotenone stations. Mar Ecol Prog Ser 206:227-237

Berumen ML, Hoey AS, Bass WH, Bouwmeester J, Catania D, Cochran JEM, Khalil MT, Miyake S, Mughal MR, Spaet JLY, Saenz-Agudelo P (2013) The status of coral reef ecology research in the Red Sea. Coral Reefs 32:737-748

Deagle BE, Gales NJ, Evans K, Jarman SN, Robinson S, Trebilco R, Hindell MA (2007) Studying seabird diet through genetic analysis of faeces: a case study on macaroni penguins (Eudyptes chrysolophus). PLoS One 2:e831

Dejean T, Valentini A, Duparc A, Pellier-Cuit S, Pompanon F, Taberlet P, Miaud C (2011) Persistence of environmental DNA in freshwater ecosystems. PLoS One 6:e23398

DiBattista JD, Berumen ML, Gaither MR, Rocha LA, Eble JA, Choat JH, Craig MT, Skillings DJ, Bowen BW (2013) After continents divide: comparative phylogeography of reef fishes from the Red Sea and Indian Ocean. J Biogeogr 40:1170-1181

DiBattista JD, Choat JH, Gaither MR, Hobbs JP, Lozano-Cortés DF, Myers RF, Paulay G, Rocha LA, Toonen RJ, Westneat M, Berumen ML (2016a) On the origin of endemic species in the Red Sea. J Biogeogr 43:13-30

DiBattista JD, Bowen BW, Gaither MR, Hobbs J-PA, Saenz-Agudelo P, Piatek M, Rocha LA, Choat JH, McIlwain J, Priest MA, Sinclair-Taylor TH, Berumen ML (2017) Comparative phylogeography of reef fishes from the Gulf of Aden to the Arabian Sea reveals two cryptic lineages. Coral Reefs 36:625-638

DiBattista JD, Roberts M, Bouwmeester J, Bowen BW, Coker DF, Lozano-Cortés DF, Choat JH, Gaither MR, Hobbs JP, Khalil M, Kochzius M, Myers R, Paulay G, Robitzch V, Saenz-Agudelo P, Salas E, Sinclair-Taylor TH, Toonen RJ, Westneat M, Williams S, Berumen ML (2016b) A review of contemporary patterns of endemism for shallow water reef fauna in the Red Sea. J Biogeogr 43:423-439

Drummond AJ, Ashton B, Cheung M, Heled J, Kearse M, Moir R, Stones-Havas S, Thierer T, Wilson A (2009) Geneious v 4.8, www.geneious.com/ 
Edgar RC (2010) Search and clustering orders of magnitude faster than BLAST. Bioinformatics 26:2460-2461

Harvey ES, Newman SJ, McLean DL, Cappo M, Meeuwig JJ, Skepper CL (2012) Comparison of the relative efficiencies of stereo-BRUVs and traps for sampling tropical continental shelf demersal fishes. Fish Res 125:108-120

Huson DH, Weber N (2012) Microbial community analysis using MEGAN. Methods Enzymol 531:465-485

Lacoursière-Roussel A, Côté G, Leclerc V, Bernatchez L (2016) Quantifying relative fish abundance with eDNA: a promising tool for fisheries management. J Appl Ecol 53:1148-1157

Leray M, Knowlton N (2015) DNA barcoding and metabarcoding of standardized samples reveal patterns of marine benthic diversity. Proc Natl Acad Sci U S A 112:2076-2081

Mahon AR, Jerde CL, Galaska M, Bergner JL, Chadderton WL, Lodge DM, Hunter ME, Nico LG (2013) Validation of eDNA surveillance sensitivity for detection of Asian carps in controlled and field experiments. PLoS One 8:e58316

Meyer CP, Paulay G (2005) DNA barcoding: error rates based on comprehensive sampling. PLoS Biology 3:e422

Miya M, Sato Y, Fukunaga T, Sado T, Poulsen JY, Sato K, Minamoto T, Yamamoto S, Yamanaka H, Araki H, Kondoh M (2015) MiFish, a set of universal PCR primers for metabarcoding environmental DNA from fishes: detection of more than 230 subtropical marine species. R Soc Open Sci 2:150088

Murray DC, Coghlan ML, Bunce M (2015) From benchtop to desktop: important considerations when designing amplicon sequencing workflows. PLoS One 10:e0124671

Pilliod DS, Goldberg CS, Arkle RS, Waits LP (2013) Estimating occupancy and abundance of stream amphibians using environmental DNA from filtered water samples. Can J Fish Aquat Sci 70:1123-1130

Pleijel F, Jondelius U, Norlinder E, Nygren A, Oxelman B, Schander C, Sundberg P, Thollesson M (2008) Phylogenies without roots? A plea for the use of vouchers in molecular phylogenetic studies. Mol Phylogenet Evol 48:369-371

Raitsos DE, Pradhan Y, Brewin RJ, Stenchikov G, Hoteit I (2013) Remote sensing the phytoplankton seasonal succession of the Red Sea. PLoS One 8:e64909

Roberts CM, Shepherd ARD, Ormond RF (1992) Large-scale variation in assemblage structure of Red Sea butterflyfishes and angelfishes. J Biogeogr 1992:239-250

Roberts MB, Jones GP, McCormick MI, Munday PL, Neale S, Thorrold S, Robitzch VS, Berumen ML (2016) Homogeneity of coral reef communities across 8 degrees of latitude in the Saudi Arabian Red Sea. Mar Pollut Bull 105:558-565

Spalding MD, Ravilious C, Green EP (2001) World atlas of coral reefs. University of California Press, Berkeley

Thomsen PF, Kielgest J, Iversen LL, Møller PR, Rasmussen M, Willerslev E (2012) Detection of a diverse marine fish fauna using environmental DNA from seawater samples. PLoS One 7:e41732 


\section{Figure legends}

328 Fig. 1 Seawater sampling sites at inshore (yellow), midshore (green), and offshore (purple) coral reefs, and a boat harbor (red) along the central Red Sea coastline near Thuwal, Saudi Arabia

Fig. 2 Number of cumulative (a) or absolute (b) genera assigned per replicate as a function of amplifiable 16S mitochondrial DNA sequences detected at seven inshore (yellow), midshore (green), and offshore (purple) coral reefs, and a boat harbor $(r e d)$ along the central Red Sea coastline near Thuwal, Saudi Arabia. SN = Shi'b Nazar; RR = Rose Reef; UAB = Um Al Balam; AFS = Al Fahal South; IF = Inner Fsar; TN = Tahla North; AS = Abu Shusha; KH =

\section{KAUST Harbor}

Fig. 3 Heatmap showing the mean number of unique 16S mitochondrial DNA sequences for each genus (a, b) detected at seven inshore (yellow), midshore (green), and offshore (purple) coral reefs, and a boat harbor (red) along the central Red Sea coastline near Thuwal, Saudi Arabia. Analyses were independently conducted using the National Center for Biotechnology Information database (a) or our custom genetic database (b). Numbers in parentheses are the number of seawater replicates that amplified per sample site. See Fig. 1 for summary of sample sites; abbreviations as in Fig. 2 


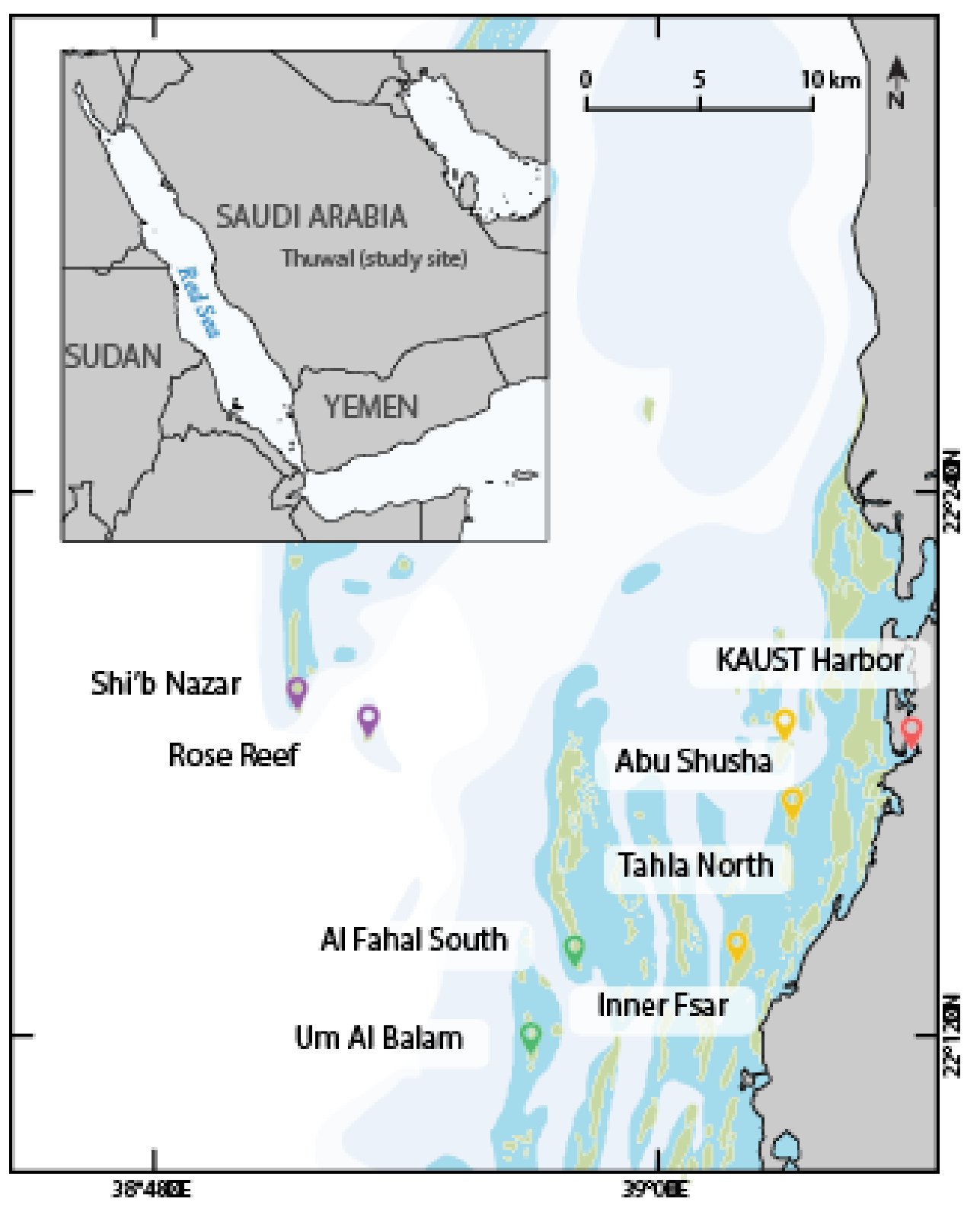



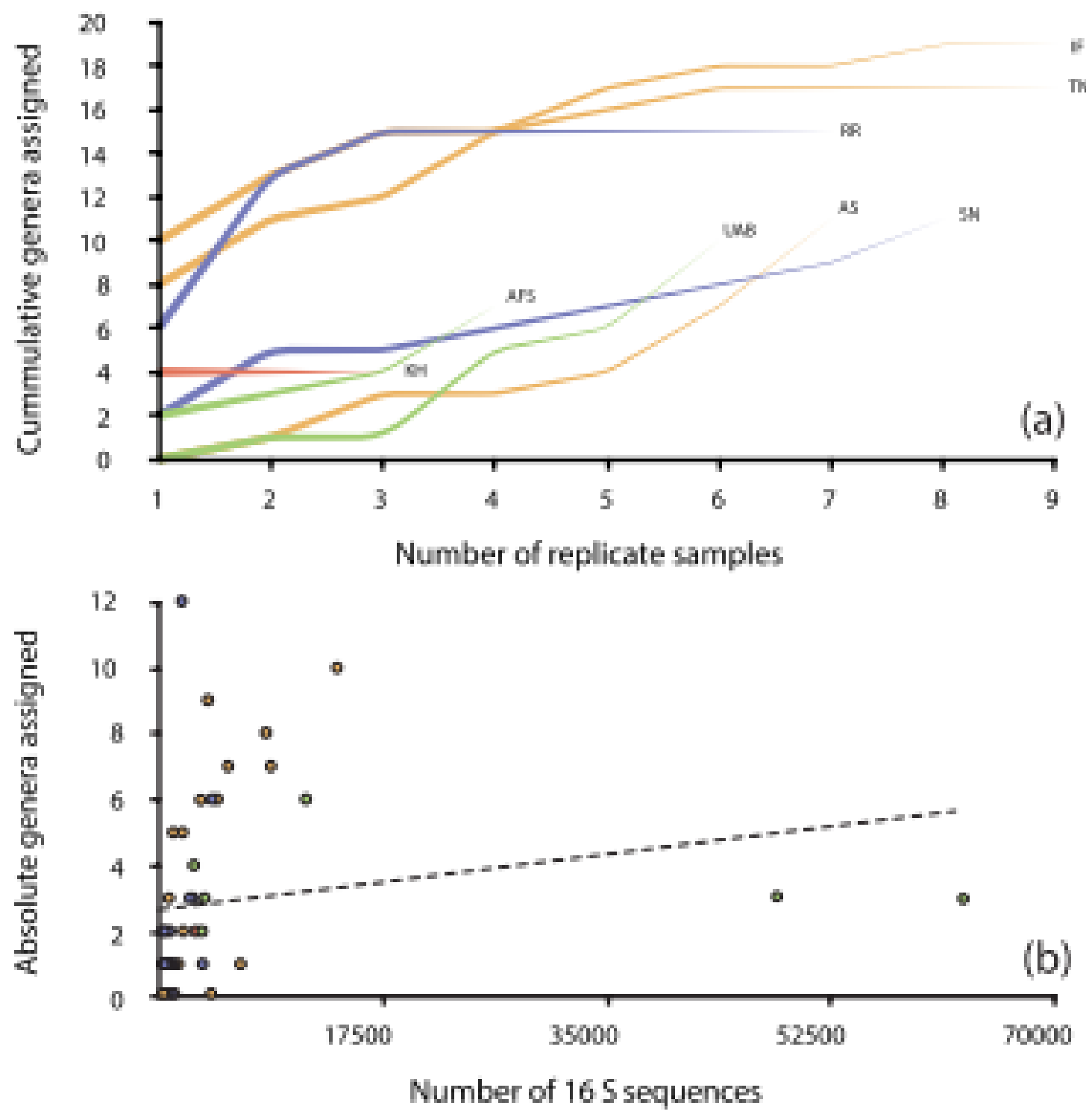


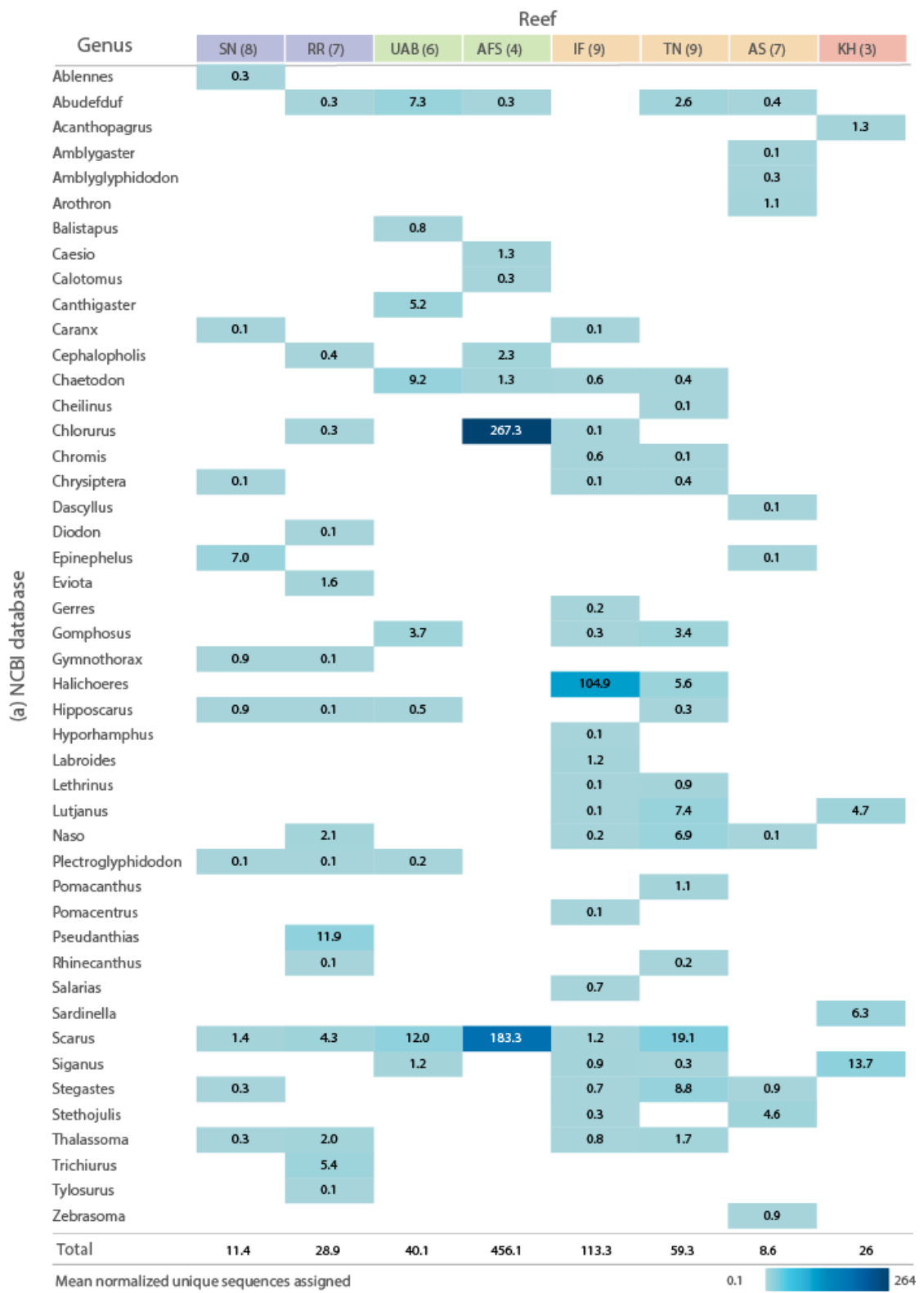

Mean normalized unique sequences assigned 


\begin{tabular}{|c|c|c|c|c|c|c|c|c|}
\hline \multirow[b]{2}{*}{ Genus } & \multicolumn{8}{|c|}{ Reef } \\
\hline & SN (8) & $\operatorname{RR}(7)$ & UAB (6) & AFS (4) & IF (9) & $\mathrm{TN}(9)$ & $\operatorname{AS}(7)$ & $\mathrm{KH}(3)$ \\
\hline Abudefduf & & 0.3 & 7.3 & 0.3 & & 2.6 & 0.4 & \\
\hline Acanthurus & 2.3 & 1.7 & 2.5 & & 0.7 & 6.1 & 2.4 & 5.3 \\
\hline Arothron & & & & & & & 1.1 & \\
\hline Balistoides & & & & & & & & 1.3 \\
\hline Caesio & & & & & & & 0.1 & \\
\hline Caranx & 0.1 & & & & & & & \\
\hline Cephalopholis & & 0.4 & & & & & & \\
\hline Chaetodon & & & & 0.5 & 0.1 & 0.1 & & \\
\hline Chlorurus & & & & 21.3 & & & 0.1 & \\
\hline Ctenochaetus & 0.3 & 0.4 & & & & 0.1 & & \\
\hline Dascyllus & & & & & & & 0.1 & \\
\hline Decapterus & 0.1 & & & & & & & \\
\hline Diodon & & 0.1 & & & & & & \\
\hline Epinephelus & 6.9 & & & & & & 0.1 & \\
\hline Labroides & & & & & 1.2 & & & \\
\hline Lethrinus & & & & & 0.1 & 0.9 & & \\
\hline Lutjanus & & 0.1 & 0.2 & 0.5 & 0.1 & 7.7 & 0.1 & 4.7 \\
\hline Macolor & & 0.6 & 1.7 & 5.5 & & & 0.4 & \\
\hline Megalaspis & & & & & 0.1 & & & \\
\hline Naso & 0.6 & 2.1 & & & 0.2 & 6.9 & 0.1 & \\
\hline Pomacanthus & & & & & & 1.1 & & \\
\hline Rhinecanthus & & 0.1 & & & & 0.2 & & \\
\hline Scarus & 1.4 & 4.3 & 12.0 & 185.0 & 1.2 & 19.4 & & \\
\hline Siganus & & & 1.2 & & 0.9 & 0.3 & & 13.7 \\
\hline Thalassoma & & 0.1 & 3.8 & & 0.6 & 3.8 & & \\
\hline Tylosurus & & & & 1.5 & 0.4 & & 0.7 & \\
\hline Total & 11.7 & 10.2 & 28.7 & 214.6 & 5.6 & 49.2 & 5.6 & 25 \\
\hline
\end{tabular}


Table 1 Summary of reef fish detected (presence/absence) at the species-level by seawater sampling at seven coral reefs and a boat harbor along the central Red Sea coastline near Thuwal, Saudi Arabia. Matches were obtained using BLASTn searches in the NCBI mitochondrial DNA 16S database or using a custom $16 \mathrm{~S}$ database (see Materials and methods). A similarity of $98 \%$ was accepted for a species-level match; to be conservative, matches at the species-level were not accepted if that taxon was not known from the Red Sea and matches were not accepted if $16 \mathrm{~S}$ sequences from all known Red Sea species within that genus were not available in each database, respectively.

\begin{tabular}{|c|c|c|c|}
\hline Family & Species & NCBI 16S database & $\underline{\text { Custom 16S database }}$ \\
\hline Acanthuridae & Ctenochaetus striatus (Quoy \& Gaimard 1825) & & $\sqrt{ }$ \\
\hline Acanthuridae & Naso brevirostris (Cuvier 1829) & & $\sqrt{ }$ \\
\hline Acanthuridae & Naso unicornis (Forsskål 1775) & $\sqrt{ }$ & \\
\hline Balistidae & Balistoides viridescens (Bloch \& Schneider 1801) & & $\sqrt{ }$ \\
\hline Balistidae & Balistapus undulatus (Park 1797) & $\sqrt{ }$ & \\
\hline Balistidae & Rhinecanthus rectangulus (Bloch \& Schneider 1801) & & $\sqrt{ }$ \\
\hline Belonidae & Ablennes hians (Valenciennes 1846) & $\sqrt{ }$ & \\
\hline Belonidae & Tylosurus crocodilus (Lesueur 1821) & $\sqrt{ }$ & $\sqrt{ }$ \\
\hline Blenniidae & Salarias fasciatus (Bloch 1786) & $\sqrt{ }$ & \\
\hline Clupeidae & Amblygaster sirm (Walbaum 1792) & $\sqrt{ }$ & \\
\hline Diodontidae & Diodon hystrix Linnaeus 1758 & $\sqrt{ }$ & \\
\hline Diodontidae & Diodon liturosus Shaw 1804 & & $\sqrt{ }$ \\
\hline Labridae & Labroides dimidiatus (Valenciennes 1839) & $\sqrt{ }$ & $\sqrt{ }$ \\
\hline Labridae & Scarus collana Rüppell 1835 & & $\sqrt{ }$ \\
\hline Labridae & Thalassoma lunare (Linnaeus 1758) & & $\sqrt{ }$ \\
\hline Labridae & Thalassoma rueppellii (Klunzinger 1828) & & $\sqrt{ }$ \\
\hline Lutjanidae & Macolor niger (Forsskål 1775) & & $\sqrt{ }$ \\
\hline Pomacanthidae & Pomacanthus maculosus (Forsskål 1775) & & $\sqrt{ }$ \\
\hline Pomacentridae & Abudefduf vaigiensis (Quoy \& Gaimard 1825) & & $\sqrt{ }$ \\
\hline Pomacentridae & Dascyllus trimaculatus (Rüppell 1829) & & $\sqrt{ }$ \\
\hline Siganidae & Siganus luridus (Rüppell 1829) & & $\sqrt{ }$ \\
\hline Siganidae & Siganus rivulatus (Forsskål 1775) & & $\sqrt{ }$ \\
\hline Sparidae & Acanthopagrus bifasciatus (Forsskål 1775) & $\sqrt{ }$ & \\
\hline
\end{tabular}

